\title{
Teacher Attributions, Seriousness of Misbehaviour and Teacher Intervention Strategies: Testing for Statistical Relationships
}

\author{
Victoria Aba Mensah \\ Department of Education, Komenda College of Education, Komenda, Ghana
}

\begin{abstract}
Given the attribution-efficacy links with seriousness of misbehaviour and teacher intervention strategies established in literature, it could be hypothesised that teacher attributions could influence seriousness of misbehaviour and teacher intervention strategies. This prompted the researcher to test for relationships between teacher attribution and the seriousness of student misbehaviour and teacher intervention strategies and seriousness of student misbehaviour. The results indicated that teacher intervention strategies have a strong relationship with seriousness of misbehaviour. This was found after the two variables (teacher intervention strategies and seriousness of misbehaviour) gave a correlation (r) result of $r=.920^{* *}, \mathrm{n}=140, \mathrm{p}=.000^{* *}, 2$-tailed) which is less than p-value of .05 . The results again showed that there is strong relationship between teacher attribution and seriousness of misbehaviour). This was palpable and evident after the two variables (teacher attributions and seriousness of misbehaviour) produced a correlation (r) result of $r=.790^{* *}, n=140, p=.003^{* *}$, $\mathrm{p}<0.05,2$-tailed) which is less than $\mathrm{p}$-value of .05 . It was therefore recommended that proactive measures should be put in place to improve teachers' intervention strategies and reduce students' misbehaviour.
\end{abstract}

Keywords: Teacher, Attributions, Seriousness, Misbehaviour, Teacher, Intervention, Strategies

DOI: $10.7176 / \mathrm{JEP} / 12-11-05$

Publication date: April $30^{\text {th }} 2021$

\section{Introduction}

Attribution theory has been explicated in the literature as a description of a process whereby the person searches for causal attributions regarding events, which in turn, influences expectations and provokes emotion along the dimensions of locus, stability, and controllability (Heider 1958). Extending Heider's work, Weiner (2010) built up a theory of motivation and emotion regarding helping behaviours. Weiner's attributional model of helping behaviour predicts that attributions about an individual's behaviour will be reliably associated with expectations and emotional responses that will tend to affect helper behaviour. More specifically, Weiner suggests that a causal attribution will have psychological consequences related to both expectancy and affect, and these consequences are then presumed to determine the action (Weiner, 2010). In his theory of self-efficacy, Bandura suggests that the impact of attributions on self-motivation occurs through the effects of the attributions on one's feelings of self-efficacy (Bandura, 1991).

Weiner (2010), attributions can be classified according to three dimensions: locus of control (external vs. internal), stability (stable vs. unstable), and controllability (controllable vs. uncontrollable). Judgments of locus address whether the cause of the behaviour resides within the individual (e.g., personality characteristics) or outside the individual (e.g., environment). Stability attributions index whether the cause is likely to be transient or present in the future. Attributions of control indicate the extent to which the cause is controllable by the individual (e.g., intentional) or uncontrollable by the individual (e.g., medical). These three dimensions originally proposed by Weiner, are among those most consistently used in research throughout the past two decades. Weiner (2010), is of the opinion that attributions may not be important in isolation, but are important because they can influence behaviour.

Dix (2012) adapted the work of Weiner to create his own model of attribution processing and outcomes. For Dix, the attribution of disposition to children is critical to the socialization process. Dix (2012) suggests that "inferring that children are intelligent, stubborn, or aggressive influences how adults react to them and which dispositions and behaviours children ultimately acquire" (p. 633). In terms of Dix's theory, there exists an extensive research base examining teachers' attribution as related to student academic achievement (Gibson \& Dembo, 2015). For example, several studies have shown that teacher attributions for academic performance affect teacher feelings of self-efficacy (Gibson \& Dembo, 2015; Tournaki \& Podell, 2005).

Attitudes and attributions are an integral part of a teacher - student relationship based on the assumption that teachers who believe they can influence student outcomes will have higher feelings of self-efficacy than teachers who feel they have little or no control over students outcomes (Gibson \& Dembo, 2015). Likewise understanding teachers' beliefs in producing positive change in the school success of their students are critically important for enhancing the ecology of the classroom, teacher-student interactions and school climate (Poulou, 2017). Teacher self-efficacy reflects teachers' evaluations about their ability to effect positive student growth, beliefs about the causes of student misbehaviour becomes important to discuss. If a teacher believes that the cause of a student's difficulty is changeable, his/her belief in his/her ability to successfully intervene may be strengthened. On the 
other hand, when she/he believes the cause of the difficulty is beyond her/him control, he/she may develop terminal thinking or learned helplessness (Heider, 1958; Weiner; 2010). For humans in general, this form of restricted thought has been implicated in the inability to establish goals and pathways to goals (Snyder, 2000), a sense of meaninglessness (Gibson \& Dembo, 2015), low levels of hope (Snyder, 2000; Weiner, 2010), and a reduced capacity for resilience in the face of adversity (Hughes, Barker, Kemenoff \& Hart, 2012).

One of our primary responsibilities as teachers is to help our students learn. It is difficult for learning to take place in chaotic environments. Subsequently, we are challenged daily to create and maintain a positive, productive classroom atmosphere conducive to learning. On any given day, this can be quite a challenge. Effective classroom management is a prerequisite of effective teaching and students' learning (Jones \& Jones, 2012) as both cannot occur in classrooms that are ineffectively managed. Student problem behaviour remains a challenging topic in schools (Conoley \& Goldstein, 2014). A major concern for teachers and school administrators is the far-reaching negative effect of problem behaviour on both delivery of instruction and student learning outcomes (Osher, Bear, Sprague, \& Doyle, 2010). A continuum of problem behaviours exhibited in school can range from small acts (e.g., pencil tapping during a whole-group lesson) to severe offences (e.g., fighting, bullying), and can come with varying levels of strength (e.g., mild, moderate, intensive). The most common problem behaviours in classrooms include; being distracted from tasks, not following directions, displaying excessive movement, and talking without permission (Harrison, Vannest, Davis, \& Reynolds, 2012). Admittedly, certain misbehaviours are typical during the developmental years and certainly, such minor infractions and transient misbehaviours are to be anticipated. However, left unchecked, milder and more common forms of child problem behaviours can, in some cases, become increasingly severe and resistant to intervention (Conoley \& Goldstein, 2014).

Teachers have considerable influence over student behaviour. This is particularly true if interventions begin early and are supported at home. Next, most student misbehaviours are learned and occur for a reason. It is our job as teachers to determine those reasons and teach appropriate behaviours to replace those misbehaviours. Prevention is the most effective form of behaviour management. That is, the most efficient way to eliminate misbehaviours is to prevent their occurrence or escalation from the beginning. Causes of student misbehaviour, especially focusing on those less serious but more frequent classroom incidents. Every teacher is confronted with student misbehaviour occasionally. The ability to resolve student misbehaviour is essential to teachers because this kind of behaviour is a threat to good discipline and requires effective management.

Most students will stop misbehaving if they receive teacher directives and learn the consequences intended to discourage the behaviour from happening again, but others will continue to engage in misbehaviour that challenges a good classroom learning environment (Brown \& Knowles, 2007). Student misbehaviour has its origin early in the lives of children (Crimmins, Farrell, Smith, \& Bailey, 2007). The origins of student classroom misbehaviour fall into four broad categories: causes that originate at home and in society, in individual students, in schools, and in teachers (Oliva \& Pawlas, 2004), this posits well in the findings of Mensah, Amponsah \& Dramanu (2020) which showed teachers' assigning causes for students' misbehaviour as student-related, family and teacher factors.

For some students, misbehaviours can become so chronic and so intense that they disrupt relationships with peers, teachers, and parents and significantly interfere with important areas of functioning (Walker et al., 2004). Doubtless, every teacher will take on a student who exhibits some type of problem behaviour, only how teachers react to problem behaviours can significantly affect the extent to which such behaviours are maintained or intensified (Lane, Gresham, \& O'Shaughnessy, 2002; Lannie \& McCurdy, 2007; Solar, 2011). The results obtained from correlation analyses indicated that coping styles mediated the relationship between teachers' concerns about student misbehaviour and their use of classroom management techniques. The findings indicated that when teachers perceived student misbehaviour as a minor concern, they tend to respond to misbehaviour by manifesting the three coping strategies. (Tran 2015) also indicated that teachers who use passive avoidant strategies employ more aggression and punishment techniques towards student misbehaviour, and use less discussion, recognition and rewards, and hinting. Conversely, teachers who use more social problem solving and relaxation strategies use more inclusive management techniques such as recognition and reward, discussion, and hinting.

The findings indicate that Vietnamese teachers increased their use of recognition and reward, discussion, and hinting to react to classroom misbehaviour. Vietnamese classrooms are seen as having most recognition and least punishment, and aggression. Misbehaviour in classes relates to the greater use of punishment and aggression. It appears that teachers who employ poor management techniques, such as punishment and aggression contribute to their own problems by reacting with passive strategies that serve only to exacerbate the very problems they are intended to overcome or prevent (Roache \& Lewis, 2011). The results of the study show that Vietnamese teachers should be encouraged to minimize the level of student misbehaviour and level of concern from schoolwork by decreasing their use of aggressive disciplinary techniques while by increasing levels of recognition and rewarding of appropriate behaviour, as well as increasing levels of discussion with 
students through professional development programs. Although a comparatively heavy body of literature exists with regard to attribution and student academic achievement, a comparatively low number of investigations have examined teachers' causal attributions for student conduct problems by testing for relationships in these variables. This study therefore sought to expand knowledge by providing empirical evidence on relationship between teacher attribution and the seriousness of student misbehaviour as well as intervention strategies and seriousness of student misbehaviour.

\section{Purpose of the Study}

The study specifically sought to:

1. Investigate the relationship between teacher attribution and the seriousness of student misbehaviour.

2. Investigate the relationship between teacher intervention strategies and seriousness of student misbehaviour.

\section{Research Hypotheses}

The study was directed by two hypotheses:

$\mathbf{H}_{0}$ 1: There is no significant relationship between teacher attribution and seriousness of misbehaviour

$\mathbf{H}_{\mathbf{0}} \mathbf{A}$ : There is significant relationship between teacher attribution and seriousness of misbehaviour

H02: There is no significant relationship between teacher intervention strategies and seriousness of misbehaviour.

$\mathbf{H}_{\mathbf{0}} \mathbf{A}$ : There is significant relationship between teacher intervention strategies and seriousness of misbehaviour.

\section{Methodology}

An explorative descriptive survey design was employed for this study. Explorative descriptive survey seeks to get replies to question through the analysis of the relationship among variables, so considering it appropriate for investigating teachers' attribution and intervention strategies to student misbehaviour. Descriptive survey is concerned with the investigation of the conditions or relationships that exist, opinions that are plain, or movements that are building up. The descriptive survey method makes the researcher to get the opinion of a representative sample of the target population so that investigation can infer the perception of the population. Shaughnessy, Zechmeister and Jeanne (2011), posited that descriptive surveys include the use of questionnaire and interview and these are all important tools for descriptive research.

Furthermore, descriptive fields are taken to demonstrate associations or relationships between things in the world and the purpose of a descriptive survey allows for a many-sided approach to data collection. As a quantitative study, the descriptive research design stood out and was appealing to this study, hence, the design selection. The accessible population was all the teachers in the three public senior high schools KEEA Municipality of the Central Region of Ghana. According to the 2018/2019 academic year senior high school (SHS) profile the total number of teachers in the three public senior high is 221. A sample size of 140 was selected from an accessible population of 221 through a cluster sampling technique. Cluster sampling (also known as one-stage cluster sampling) is a technique in which clusters of participants that represent the population are identified and included in the sample. An example of cluster sampling is area sampling or geographical cluster sampling. Each cluster is a geographical area. The sample for the study comprises of 140 respondents, consisting of 46 teachers selected from each area cluster using simple random sampling.

The study employed a "Teacher's Attributions for Student's Behaviour Measure" adapted from Simms (2014) and Ding (2010) as the instrument for the study. In an effort to ensure both face validity and content validity, experts in the field reviewed the TASBM and provide feedback regarding the clarity of the scenarios used, the relevance of items in the scale, and the extent to which the behaviours in the scenarios where sample behaviours representative of the range of problem behaviours typically displayed by pupils.

The data was analysed using inferential statistics (Pearson Product Moment of correlation). Correlation determines the direction of a relationship between variables. The Pearson product moment correlation coefficient (PPMCC) varies between -1 (negative correlation) through 0 (no correlation) to +1 (positive correlation). This means that a correlation that fall within 0.6 to 1 shows a strong correlation between the variables.

\section{RESULTS}

Hypotheses One: Ho1: There is no significant relationship between teachers' attribution and seriousness of student misbehaviour.

One of the main purposes of the study was to find out whether there is a relationship between teacher attribution and seriousness of misbehaviour. To determine this, Pearson product moment correlation was used for the analysis. The results are presented in Table 1. 
Table 1: Correlation Results of Teacher Attribution and Seriousness of Misbehaviour

\begin{tabular}{|c|c|c|c|}
\hline \multicolumn{2}{|c|}{ Study Variables (TA * SM) } & $\begin{array}{l}\text { Teacher Attribution } \\
\text { (TA) }\end{array}$ & $\begin{array}{c}\text { Seriousness of Misbehaviour } \\
\text { (SM) }\end{array}$ \\
\hline \multirow{2}{*}{$\frac{\text { Teacher }}{\text { (TA) }}$} & on Pearson Correlation & 1 & $.790 * *$ \\
\hline & Sig. (2-tailed) & & $.003 * *$ \\
\hline \multirow{4}{*}{$\begin{array}{l}\text { Seriousness } \\
\text { Misbehaviour (SM) }\end{array}$} & $\mathrm{N}$ (observations) & 140 & 140 \\
\hline & of Pearson Correlation & $.790 * *$ & 1 \\
\hline & Sig. (2-tailed) & $.003 * *$ & \\
\hline & N (observations) & 140 & 140 \\
\hline
\end{tabular}

\section{Source: Field Survey, (2020) *. $\mathrm{P}=0.05$ level (2-tailed)}

Table 1 illustrates the result of relationship teacher attribution and seriousness of student misbehaviour. The results from the study gives evidence that teacher attribution has a strong relationship with seriousness of misbehaviour. The correlation $(r)$ results produced a statistical significant relationship between the two variables (teacher attribution and seriousness of misbehaviour). This was obvious after the two variables (teacher attribution and seriousness of misbehaviour) gave a correlations $(r)$ results of $r=.790^{* *}, \mathrm{n}=140, p=.003^{* *}$, $p<0.05$, 2-tailed) which is less than $p$-value of .05. This therefore, indicates that teacher attribution determines the seriousness of misbehaviour of students. The null hypothesis stated as "there is no significant relationship between teachers' attribution and seriousness of student misbehaviour" was therefore rejected in favour of the alternative hypothesis.

Hypotheses Two: $H_{0}$ : There is no significant relationship between teacher intervention strategies and seriousness of student misbehaviour.

One of the purposes of the paper was determine whether there is a relationship between teacher intervention strategies and seriousness of misbehaviour. To determine this, Pearson product moment correlation (PPMC) was used for the analysis. The results are presented in Table 2.

Table 2: Correlation Results of Teacher Intervention Strategies and Seriousness of Misbehaviour

\begin{tabular}{|c|c|c|c|}
\hline \multicolumn{2}{|c|}{ Study Variables (IS * SM) } & $\begin{array}{c}\text { Intervention Strategies } \\
\text { (IS) }\end{array}$ & $\begin{array}{c}\text { Seriousness of Misbehaviour } \\
\text { (SM) }\end{array}$ \\
\hline \multirow{3}{*}{$\begin{array}{l}\text { Intervention } \\
\text { Strategies (IS) }\end{array}$} & Pearson Correlation (r) & 1 & $.920 * *$ \\
\hline & Sig. (2-tailed) & & $.000 * *$ \\
\hline & N (observations) & 140 & 140 \\
\hline \multirow{2}{*}{$\begin{array}{l}\text { Seriousness } \\
\text { Misbehaviour } \\
\text { (SM) }\end{array}$} & Pearson Correlation (r) & $.920 * *$ & 1 \\
\hline & $\begin{array}{l}\text { Sig. }(2 \text {-tailed) } \\
\text { N (observations) }\end{array}$ & $\begin{array}{c}.000 * * \\
140\end{array}$ & 140 \\
\hline
\end{tabular}

Source: Field Survey (2020) * $\mathrm{P}=0.05$ level (2-tailed)

Table 2 presents the results of the relationship among teacher intervention strategies and seriousness of misbehaviour. As shown in Table 2, the results from the analysis revealed that teacher intervention strategies have a strong relationship with seriousness of misbehaviour. The correlation $(r)$ produced a statistical significant relationship between the two variables (teacher intervention strategies and seriousness of misbehaviour).

This was after the two variables (teacher intervention strategies and seriousness of misbehaviour) gave a correlation $(r)$ result of $r=.920^{* *}, \mathrm{n}=140, \mathrm{p}=.000^{* *}, 2$-tailed which is less than $p$-value of .05 . This therefore, indicates that the kind of teacher intervention strategies determines the seriousness of misbehaviour of students. The null hypothesis stated as "there is no significant relationship between teacher intervention strategies and seriousness of student misbehaviour" was therefore rejected in favour of the alternative hypothesis.

\section{Relationship between Teacher Attributions and Seriousness of Misbehaviour}

The results from the study give evidence to suggest that teacher attribution has a strong relationship with seriousness of misbehaviour. The correlation $(r)$ results produced a statistical significant relationship between the two variables (teacher attribution and seriousness of misbehaviour). This showed that the two variables (teacher attribution and seriousness of misbehaviour) gave a correlation $(r)$ result of $r=.790 * *, \mathrm{n}=140, p=.003 * *$, $p<0.05,2$-tailed) which is less than $p$-value of .05 . This therefore, indicates that teacher attribution determined the seriousness of misbehaviour of students.

When looking across all possible factors' student, teacher, family and school - the researcher found out that senior high school teachers seemed to hold perceptions similar to teachers in many other studies (Bibou-Nakou, Kiosseoglou, \& Stogiannidou, 2000; Mavropoulou \& Padeliadu, 2002; Mensah, Amponsah \& Dramanu, 2020), that is, an external attribution for students' misbehaviours rather than looking for reasons from themselves. According to the researchers of previous studies, when teachers seek external attributions for student 
misbehaviour, they might tend to take less responsibility or show less self-confidence in behavioural management. However, the teachers' sample's preferred and most commonly used strategies (e.g., "teach the student a different way" "talking after class" and "praising good students") are all teacher-based approaches, which suggested that their external attribution was not a negative sign. Soodak and Podell also agreed that teachers who used more teacher-based strategies had greater self-confidence in dealing with misbehaviours.

\section{Relationship between Teacher Intervention Strategies and Seriousness of Misbehaviour}

The results of the study showed that teacher intervention strategies had a relationship with seriousness of misbehaviour. The results of the analysis revealed is stated as $r=.920^{* *}, \mathrm{n}=140, \mathrm{p}=.000^{* *}, 2$-tailed) which is less than $p$-value of .05 . The results confirmed the attribution theory by Weiner's (2010). According to Weiner's, attribution model of helping behaviour predicts that attributions about an individual's behaviour will be reliably associated with expectations and emotional responses that will tend to affect helper behaviour. Specifically, Weiner suggested that a causal attribution will have psychological consequences related to both expectancy and affect, and these consequences are then presumed to determine the action (Weiner, 2010). Likewise, in Bandura in his theory of self-efficacy, suggested that the impact of attributions on self-motivation occurs through the effects of the attributions on one's feelings of self-efficacy and such as teacher's intervention strategies have association with seriousness of misbehaviour. Teacher self-efficacy reflects teachers' evaluations about their ability to effect positive student growth, beliefs about the causes of student misbehaviour becomes important to discuss. If a teacher believes that the cause of a student's difficulty is changeable, his/her belief in his/her ability to successfully intervene may be strengthened. On the other hand, when she/he believes the cause of the difficulty is beyond her/him control, he/she may develop terminal thinking or learned helplessness (Heider, 1958; Weiner; 2010). For humans in general, this form of restricted thought has been implicated in the inability to establish goals and pathways to goals (Snyder, 2000), a sense of meaninglessness (Gibson \& Dembo, 2015), low levels of hope (Snyder, 2000; Weiner, 2010), and a reduced capacity for resilience in the face of adversity (Hughes, Barker, Kemenoff \& Hart, 2012).

\section{Conclusions and Recommendations}

The study gave evidence to believe that generally, teachers in K. E. E. A. attributions could lead or influence seriousness of their students' misbehaviour. In the case of teacher intervention strategies and seriousness of misbehaviour, the results were not different as strong relationship existed between the two variables. It is recommended that since school factors were identified as one of the breeding grounds for student misbehaviour. It is recommended that the school authorities put strategies in place to control and mange students' behaviours and reactions. Again, since relationships exist between proactive measures should be put in place to improve teachers' intervention strategies and reduce students' misbehavior in classrooms. Using a proactive approach also allows us to focus more on teaching appropriate behaviours rather than eliminating negative behaviours. Our experience tells us that management systems should be flexible enough to meet the changing needs of our classrooms. Finally, students, parents, and other professionals can be effective partners in behaviour management.

\section{References}

Atici, M., \& Merry, R. (2001). Misbehaviour in British and Turkish primary classrooms. Pastoral Care, 19(2), 32-39.

Bibou-Nakou, I. Kiosseoglou, G. \& Stogiannidou, A. (2000). Elementary teachers' perceptions regarding school behaviour problems: Implications for school psychological services. Psychology in the Schools, 37(2), 123134.

Conoley, J. C. \& Goldstein, A. P. (2014). School violence intervention: A practical handbook (2 ${ }^{\text {nd }}$ ed.). New York: Guilford.

Ding, M. (2010) Chinese teachers' attributions and intervention strategies for student classroom misbehaviour, Asia Pacific Journal of Education, 30:3, 321-337, DOI: 10.1080/02188791.2010.495832.

Dix, T. (2012). Attributing dispositions to children, an interactional analysis of attribution to socialization. Personality and Social Psychology, 19(5), 623-643.

Gibson, S., \& Dembo, M. (2015). Teacher efficacy: A construct validation. Journal of Educational Psychology, 76(4), 569-582.

Gresham, F. M., Cook, C. R., Crews, S. D., \& Kern, L. (2004). Social skills training for children and youth with emotional and behavioural disorders: Validity considerations and future directions. Behavioural Disorders, $30,32-46$

Harrison, J. R., Vannest K., Davis, J., \& Reynolds, C. (2012). Common problem behaviours of children and adolescents in general education classrooms in the United States. Journal of Emotional and Behavioural Disorders March, 20, 55-64. 
Heider, F. (1958). The Psychology of Interpersonal Relations. Oxford: Wiley.

Ho, I.T. (2004). A comparison of Australian and Chinese teachers' attributions for student problem behaviours. Educational Psychology, 24, 375-391.

Hughes, J. N., Barker, D., Kemenoff, S., \& Hart, M. (2012). Problem ownership, causal attributions, and selfefficacy as predictors of teachers' referral decisions. Journal of Educational and Psychological Consultation, 4, 369-384.

Kauffman, J. M. (2001). Characteristics of emotional and behavioural disorders of children and youth ( $7^{\text {th }}$ ed.). New York: Merrill.

Lannie, A. L., \& McCurdy, B. L. (2007). Preventing disruptive behaviour in the urban classroom: Effects of the good behaviour game on student and teacher behaviour. Education \& Treatment of Children, 30(1), 85-98.

Mavropoulou, S., \& Padeliadu, S. (2002). Teachers' causal attributions for behaviour problems in relation to perceptions of control. Educational Psychology, 22, 191-202.

Mensah, V. A., Amponsah, M. O., \& Dramanu, B. Y. (2020). Teachers' Attributions and Intervention Strategies for Students' Classroom Misbehaviours: Evidence from Senior High Schools in Komenda Edina Eguafo Abrem Municipality. Journal of Education, Society and Behavioural Science,33(11), 39-47. https://doi.org/10.9734/jesbs/2020/v33i1130270

Osher, D., Bear, G. G., Sprague, J. R., \& Doyle, W. (2010). How can we improve school discipline? Educational Researcher, 39, 48-58. doi: 10.3102/0013189X09357618.

Roache, S., \& Lewis. R. (2011). Teachers' views on the impact of classroom management on student responsibility. Australian Journal of http://dx.doi.org/10.1177/000494411105500204

Shaughnessy, J., Zechmeister, E., \& Jeanne, Z. (2011). Research methods in psychology (9th ed.). New York, NY: McGraw Hill. pp. 161-175.

Simms, A.P. (2014). The Relationship between Teachers' Causal Attributions for Student Problem Behaviour and Teachers' Intervention Preferences. A doctoral dissertation submitted to the Kent State University College.

Snyder, C.R. (2000). Handbook of Hope: Theory, Measures, and Applications. California: Academic Press.

Solar, E. (2011). Prove them wrong. Teaching Exceptional Children, 44(1), 40-45 Silvester, J., Mohamed, A. R., Anderson-Gough, F., \& Anderson, N. R. (2002). Locus of control, attributions and impression management in the selection interview. Journal of Occupational \& Organizational Psychology, 75(1), 59-76.

Soodak, L, C \& Podell, D. M (1997) Efficacy and experience: Perceptions of efficacy among preservice and practicing teachers. Journal of research and development in education, 30(4), 214-221.

Soodak, L., \& Podell, D.M. (1994). Teachers' thinking about difficult-to-teach students. Journal of Educational Research, 88, 44-51.

Tournaki, N., \& Podell, D. (2005). The impact of student characteristics and teacher efficacy on teacher's predications of student success. Teaching and Teacher Education, 21, 299-314. doi:10.1016/j.tate.2005.01.003.

Tran, V. D. (2015) Coping Styles with Student Misbehavior as Mediators of Teachers' Classroom Management Strategies. International Journal of Higher Education Vol. 5, No. 1; 2016 doi:10.5430/ijhe.v5n1p1

Walker, H. M., Ramsey, E., \& Gresham, F. M. (2004). Antisocial behaviour in school: Evidence-based practices ( $2^{\text {nd }}$ ed.). Belmont, CA: Wadsworth.

Weiner, B. (2010). Some methodological pitfalls in attribution research. Journal of Educational Psychology, 75 , 530-543. 